\title{
Impact of a Mindfulness Intervention on Hospice Care Worker Safety and Well-Being
}

Morgan A. Valley ${ }^{1,}{ }^{*}$, Lorann Stallones ${ }^{2}$

1. Department of Environmental \& Radiological Health Sciences, Colorado State University, Fort Collins, CO 80523-1879, USA; E-Mail: Morgan.Valley@colostate.edu

2. Department of Psychology, Colorado State University, Fort Collins, CO 80523-1879, USA; E-Mail: Lorann.Stallones@colostate.edu

* Correspondence: Morgan A. Valley; E-Mail: Morgan.Valley@colostate.edu

Academic Editor: Viann N. Nguyen-Feng

Special Issue: $\underline{\text { Yoga and Mindfulness }}$

OBM Integrative and Complementary Medicine

2021, volume 6 , issue 3

doi:10.21926/obm.icm.2103029
Received: June 30, 2021

Accepted: September 06, 2021

Published: September 12, 2021

\begin{abstract}
Hospice care workers are exposed to the hazards associated with in-home care in uncontrollable environments as well as occupational stress related to caring for terminally ill patients and their families. This study aimed to assess the effectiveness of an abbreviated mindfulness intervention to improve hospice care worker occupational safety performance and well-being. This study used a single-group pre-post design to pilot test an 18-hour mindfulness training as an intervention on self-reported safety performance and well-being among 13 hospice care workers in Colorado. Participants reported statistically increased levels of safety compliance, one component of safety performance, and subjective well-being following the abbreviated mindfulness intervention in comparison to baseline. The findings that mindfulness training can improve self-reported safety compliance and well-being among hospice workers support further testing of the use of abbreviated mindfulness trainings within hospice care organizations to promote worker safety and well-being.
\end{abstract}

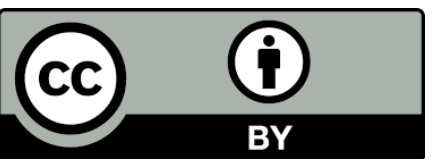

(C) 2021 by the author. This is an open access article distributed under the conditions of the Creative Commons by Attribution License, which permits unrestricted use, distribution, and reproduction in any medium or format, provided the original work is correctly cited. 


\section{Keywords}

Mindfulness; hospice workers; safety; well-being

\section{Introduction}

Statement of the Problem. Occupational health and safety and stress represent significant public health problems among hospice care workers, who are exposed to the hazards associated with inhome care in uncontrollable environments [1] as well as the occupational stressors of caring for terminally ill patients and their families [2].

Mindfulness training, which aims to increase present-focused nonjudgmental awareness among participants [3], has become an increasingly common component of workplace wellness programs [4-6]. Recent meta-analyses of workplace mindfulness-based intervention found that a growing body of evidence that suggests that mindfulness can reduce stress, improve well-being and components of job performance $[7,8]$. Research on health care workers has shown to increase worker well-being [9-11]. While a growing body of evidence supports the positive impact of mindfulness training on the well-being of the broader healthcare provider workforce, only a small subset of these studies focuses on hospice care workers. Studies on mindfulness among hospice care workers suggest that brief mindfulness training lessens anxiety, compassion fatigue [12], and factors that lead to burnout, such as depersonalization [13].

Research on the relationship between mindfulness and occupational safety outcomes is in its nascency and largely relies on cross-sectional survey research, e.g. [14-16]. Our early research on the impact of mindfulness training on occupational safety [17] found that the gold standard of mindfulness training, Mindfulness-Based Stress Reduction (MBSR), significantly improved safety compliance. However, participants viewed the MBSR course, which consists of 36-hours of training as too time intensive and impractical for healthcare workers [17].

\subsection{Purpose}

This study used a single-group pre-post design to pilot test the impact of an abbreviated mindfulness training on hospice care worker safety and well-being.

This study had two hypotheses:

Hypothesis 1: The brief mindfulness intervention will increase study participants' workplace safety performance.

Hypothesis 2: The brief mindfulness intervention will increase study participants' overall wellbeing.

This study contributes to the understanding of the relationship between mindfulness and worker safety performance and well-being in the hospice care setting.

\section{Materials \& Methods}

Participants were recruited from a Colorado-based hospice care organization that provides inhome and in-patient care services to people with serious long-term illnesses, those navigating the last months of life, and supportive services to their families. To recruit participants, the study team 
posted promotional flyers in the staff break room, and the organization's administration team sent promotional materials with the description of the study by email to all employees of the organization and invited employees to participate at staff meetings.

The intervention, modified from Fortney and colleagues [9] included five group mindfulness training sessions in May and June 2016. Three of the sessions occurred over an-intensive weekend outside of work and two additional sessions occurred at work. The 18-hour training was designed to teach participants to incorporate mindfulness into their daily lives at work and outside of work. Participants received instruction in mindfulness practices including walking meditation, sitting meditation focusing on breathing, body scans, gentle yoga, and guided visualizations. The training sessions also contained an overview of evidence on mindfulness training and hospice-care specific recommendations. During group discussions, participants were encouraged to share their experiences in adopting the mindfulness practices at work and outside of work. The training was led by a physician facilitator experienced in leading mindfulness training. The study was reviewed and approved by the Colorado State University Institutional Review Board.

\subsection{Data Collection \& Measures}

Participants completed surveys at baseline and after the mindfulness training. Demographic variables including age, gender, race and ethnicity, provider type, and prior experience with mindfulness practices were assessed at baseline. Mindfulness, safety performance, and well-being were assessed at baseline and post-intervention.

As a manipulation check, we measured mindfulness using the Brief Five Facets of Mindfulness Questionnaire [18] which measures acting with awareness, describing, non-reactivity, nonjudgment of inner experiences, and observing on a 5-point scale ranging from "never or rarely true" to "very often or always true."

\subsection{Outcome Measures}

We used Neal, Griffin, and Hart's [19] 8-item measure of workplace safety performance that assesses safety compliance (e.g., "I use the correct safety procedures for carrying out my job") and safety participation (e.g., "I voluntarily carry out tasks or activities that help to improve workplace safety") on a 5-point scale ranging from "Strongly Disagree" to "Strongly Agree." Although many studies have examined safety performance as a unidimensional composite variable, Griffin and Neal's research findings [20] suggest that safety compliance and participation offer distinct facets of safety performance. As such, we assessed the facets separately. We assessed participants' subjective well-being using Diener et al.'s [21] 8-item flourishing scale (e.g., "I lead a purposeful and meaningful life") on a 5-point scale ranging from "Strongly Disagree" to "Strongly Agree."

Participants also answered a series of open-ended questions in the post-intervention survey about their perceptions of the impact of the training on their lives.

\subsection{Statistical Analyses}

Mean scores of study variables were calculated for participants at baseline and post-intervention. We tested the study variables for normality using Kolmogorov-Smirnov and Shapiro-Wilk tests. For all variables, the $p$-values were larger than 0.05 , suggesting that there is no reason to think that our 
data differs significantly from a normal distribution. Three paired t-tests were used to compare participants' mean safety participation, safety compliance, and subjective well-being scores from baseline to post-intervention. An adjusted alpha rate of .013 was used to control for multiple comparisons. We used SPSS version 22 (IBM) to analyze the data.

\section{Results}

\subsection{Participants}

Thirteen Caucasian female hospice workers participated in the study. Ages of participants ranged from 33-years-old to 65-years-old, with a median age of 49 years. Participants held a mix of roles in hospice care, including, grief counselor, RN (In-home care and in-patient care), music therapist, dispatcher, and chaplain. Of the 13 participants, nine reported practicing meditation prior to the study, and 11 reported practicing yoga prior to the study.

One participant did not complete the post-survey and was excluded from the analysis. There were no other missing data.

\subsection{Participation in the Intervention}

Of the 13 participants, nine attended all five mindfulness training sessions, and the remaining four participants attended four of the five sessions. Reasons cited for missing a session included personal or family illness, work obligations, and other commitments outside of work.

\subsection{Change in Mindfulness}

There was an increase in participants' mindfulness scores, although the increases in the describe and non-reactivity facets of mindfulness weren't statistically significant (see Table 1). This analysis, done as a manipulation check, indicates that the intervention resulted in changes in mindfulness scores in the expected direction.

Table 1 Means, Standard Deviations, and Paired T-Test Results of Baseline (May 2016) and Post-Intervention (June 2016) Mindfulness, Safety Performance, and Well-being.

\begin{tabular}{llllll}
\hline & $\begin{array}{l}\text { Baseline } \\
M[S D]\end{array}$ & $\begin{array}{l}\text { Post-Intervention } \\
M[S D]\end{array}$ & $d f$ & $T$ & Sig. \\
\hline Mindfulness & & & & & \\
Describe & $3.55[0.53]$ & $3.77[0.58]$ & 11 & -1.82 & .097 \\
Non-Reactivity & $3.13[0.39]$ & $3.4[0.49]$ & 11 & -2.07 & .063 \\
Non-Judgment & $3.58[0.52]$ & $4.17[0.41]$ & 11 & -5.12 & $<.001$ \\
Observe & $4.04[0.55]$ & $4.38[0.38]$ & 11 & -3.55 & .005 \\
Act with Awareness & $3.01[0.54]$ & $3.45[0.42]$ & 11 & -3.03 & .012 \\
Safety Performance & & & & & \\
Safety Compliance & $3.81[0.54]$ & $4.27[0.71]$ & 11 & -3.07 & .011 \\
\hline
\end{tabular}




\begin{tabular}{llllll}
\hline Safety Participation & $3.29[0.47]$ & $3.81[0.62]$ & 11 & -2.01 & .069 \\
Well-Being & $4.02[0.20]$ & $4.44[0.44]$ & 11 & -3.25 & .008 \\
\hline
\end{tabular}

Note. $M=$ mean; $S D=$ Standard Deviation; $d f$ = degrees of freedom; $T$ = T-statistic; sig = p-value. Mindfulness was measured on a 5-point scale with higher scores representing more mindful [18]. Safety performance (including safety compliance and participation) was measured on a 5-point scale [19] with higher score representing increased safety compliance or participation. Wellbeing was measured on a 5-point scale [21] with higher score representing higher well-being.

\subsection{Changes in Key Outcomes}

There was a significant increase in participants' mean safety compliance scores from baseline (M $=3.81, \mathrm{SD}=0.54)$ to post-intervention $(\mathrm{M}=4.27, \mathrm{SD}=0.71) ; \mathrm{t}(11)=-3.07, \mathrm{p}=.011$. Although participants' mean safety participation scores increased from baseline $(M=3.29, S D=0.47)$ to postintervention $(M=3.81, S D=0.62)$, this change was not significant $t(11)=-2.01, p=.069$. These findings partially supported Hypothesis 1 , which predicted that participants would have an increase in their workplace safety performance.

There was also a significant increase in participants' mean subjective well-being scores from baseline $(M=4.02, S D=0.20)$ to post-intervention $(M=4.44, S D=0.44)$; $(11)=-3.25, p=.008$. These findings supported the study's Hypothesis 2 that the brief mindfulness intervention will increase study participants' overall well-being.

In addition to the measures on key outcomes, participants shared how the mindfulness training impacted their lives. They described how the training led to positive internal changes. For example, one participant wrote, "I find myself being more in tune with my surroundings, I have noticed I eat my food more mindfully and slowly. When I do practice sitting meditation, I find my sense of ease is greatly enhanced. I seem to have a lightness about me. I have noticed I don't feel as rushed during my day even though I have just as much to do."

Other participants described improvements in their interactions with their families, co-workers, and patients. For example, one participant wrote, "I think I am more present to my clients and can help them in anxiety and stress reduction by practicing the techniques I learned. I am "paying it forward" to help others." Another wrote, "Being with a group of coworkers all interested in exploring mindfulness has impacted my work relationships with those people in a very positive way."

One participant stated that she didn't experience positive changes at work because of the unchanged demands at work, stating, "Sadly I haven't really had positive changes at work. Maybe some breathing when stressed with too much work. Often our case load leaves no time for much else. My last four shifts have been 12 hours of non-stop. I eat in the car on the way to my next visit. I get no lunch break."

Following the intervention, the participants advocated for continued mindfulness training for staff. In response, the organization dedicated space for employees to practice mindfulness during work and continued offering group mindfulness practice sessions.

\section{Discussion}

This pilot study of an 18-hour mindfulness intervention among 13 hospice care workers found that mindfulness training can improve self-reported safety compliance and subjective well-being. 
Consistent with our prior study on mindfulness training and safety performance [17], this study found that mindfulness training only significantly increased the safety compliance component of safety performance, which involves following safety rules and regulations. The increases in mean scores by a third to half of a point represents a meaningful change. For example, the mean score for safety compliance increased from 3.81, which represents sometimes following safety guidelines, to 4.27, which represents usually following safety guidelines.

There was a non-significant increase on safety participation. This may be due to this study's small sample size or that safety participation requires more active advocacy of safety within the workplace that goes beyond internal changes that mindfulness sparks.

This study's findings align with the growing body of evidence that suggests mindfulness training positively impacts health care worker well-being [9-11]. The Covid-19 pandemic has increased demand for hospice care workers while simultaneously increasing their workloads and potential for exposure to illness, which has compounded strains experienced on the job [22]. This underscores the critical need for continued and increased efforts to improve health care worker well-being that include hospice care workers.

The results of this study's manipulation check found increases in all five mindfulness facets among participants. However, the increases in the describe and non-reactivity facets of mindfulness weren't statistically significant. A recent systematic review of randomized controlled trials on mindfulness training among health care workers found that 15 studies reported training resulted in significant increases the mindfulness facets except for non-reactivity [11]. The authors of the review hypothesized that some facets of mindfulness, like non-reactivity, may take longer to develop while noting that existing literature does not explore the relationships between individual facets of mindfulness and key outcomes. While this study was not designed to explore relationships between changes in individual mindfulness facets and workplace safety and wellbeing, we would expect that each of the facets would uniquely benefit the well-being of hospice care workers while also impacting the quality of care they provide.

\subsection{Limitations and Future Research}

The results of this pilot study are limited by its reliance on a small sample of hospice workers from a single hospice organization, its lack of comparison group, and lack of long-term follow-up. The study used self-reported proximal outcomes for occupational safety and did not address organizational safety factors. Additionally, the sample included volunteers who were highly motivated to learn mindfulness practices, and many came into the study with prior experience practicing mindfulness and yoga. We were unable to conduct multivariate analyses to examine differences in the intervention's effectiveness by participant characteristics such as gender and racial identities due to both the small sample size and the homogeneous sample.

Future research can build on this study to investigate the role of mindfulness practice on both individual and organizational factors related to occupational safety and well-being among hospice care workers. Additionally, more research exploring the role of mindfulness training components on individual mindfulness facets and subsequent psychological outcomes would help reveal the underlying mechanism in mindfulness training and aid in training development. 


\subsection{Practical Implications}

The findings of this study suggest that mindfulness training can be used within hospice care organizations as an intervention that can impact workplace safety and overall worker well-being among hospice care workers.

\section{Acknowledgments}

We would like to acknowledge Dr. Michael Towbin for his time, expertise, dedication, and contribution to the mindfulness training.

\section{Author Contributions}

Dr. Lorann Stallones contributed to the design of the study, establishment of partnerships with the hospice care organization and mindfulness training facilitator, and manuscript development and refinement. Dr. Morgan Valley contributed to the design of the study, selection and development of study measures, data collection, data analysis, and manuscript development and refinement.

\section{Funding}

This publication was made possible with support from the Oregon Healthy Workforce Center, U19 OH010154 and funding from the Colorado Injury Control Research Center.

\section{Competing Interests}

The authors have declared that no competing interests exist.

\section{References}

1. Centers for Disease Control and Prevention. NIOSH hazard review: Occupational hazards in home healthcare [Internet]. Cincinnati: Centers for Disease Control and Prevention; 2010. Available from: https://www.cdc.gov/niosh/docs/2010-125/default.html.

2. Peters L, Cant R, Sellick K, O'Connor M, Lee S, Burney S, et al. Is work stress in palliative care nurses a cause for concern? A literature review. Int J Palliat Nurs. 2012; 18: 561-567.

3. Kabat-Zinn J. Full catastrophe living: The program of the stress reduction clinic at the University of Massachusetts Medical Center. New York: Delacorte Press; 1990.

4. Glomb TM, Duffy MK, Bono JE, Yang T. Mindfulness at work. In: Research in personnel and human resources management. Bingley: Emerald Group Publishing Limited; 2011.

5. Good DJ, Lyddy CJ, Glomb TM, Bono JE, Brown KW, Duffy MK, et al. Contemplating mindfulness at work: An integrative review. J Manag. 2016; 42: 114-142.

6. Wolever RQ, Bobinet KJ, McCabe K, Mackenzie ER, Fekete E, Kusnick CA, et al. Effective and viable mind-body stress reduction in the workplace: A randomized controlled trial. J Occup Health Psychol. 2012; 17: 246-258.

7. Lomas T, Medina JC, Ivtzan I, Rupprecht S, Eiroa-Orosa FJ. Mindfulness-based interventions in the workplace: An inclusive systematic review and meta-analysis of their impact upon wellbeing. J Posit Psychol. 2019; 14: 625-640.

8. Vonderlin R, Biermann M, Bohus M, Lyssenko L. Mindfulness-based programs in the workplace: 
A meta-analysis of randomized controlled trials. Mindfulness. 2020; 11: 1579-1598.

9. Fortney L, Luchterhand C, Zakletskaia L, Zgierska A, Rakel D. Abbreviated mindfulness intervention for job satisfaction, quality of life, and compassion in primary care clinicians: A pilot study. Ann Fam Med. 2013; 11: 412-420.

10. Irving JA, Dobkin PL, Park J. Cultivating mindfulness in health care professionals: A review of empirical studies of mindfulness-based stress reduction (MBSR). Complement Ther Clin Pract. 2009; 15: 61-66.

11. Kriakous SA, Elliott KA, Lamers C, Owen R. The effectiveness of mindfulness-based stress reduction on the psychological functioning of healthcare professionals: A systematic review. Mindfulness. 2021; 12: 1-28.

12. Watts KJ, O'Connor M, Johnson CE, Breen LJ, Kane RT, Choules K, et al. Mindfulness-based compassion training for health professionals providing end-of-life care: Impact, feasibility, and acceptability. J Palliat Med. 2021. Doi: 10.1089/jpm.2020.0358.

13. Essary AC, Lussier M, Stone N, Volk-Craft B, Hamilton G. Reflections on the integration of a narrative medicine and mindfulness program in hospice and palliative care. Prog Palliat Care. 2020; 28: 260-266.

14. Dierynck B, Leroy H, Savage GT, Choi E. The role of individual and collective mindfulness in promoting occupational safety in health care. Med Care Res Rev. 2017; 74: 79-96.

15. Zhang J, Ding W, Li Y, Wu C. Task complexity matters: The influence of trait mindfulness on task and safety performance of nuclear power plant operators. Pers Individ Differ. 2013; 55: 433-439.

16. Zhang J, Wu C. The influence of dispositional mindfulness on safety behaviors: A dual process perspective. Accid Anal Prev. 2014; 70: 24-32.

17. Valley MA, Stallones L. Effect of mindfulness-based stress reduction training on health care worker safety. J Occup Environ Med. 2017; 59: 935-941.

18. Bohlmeijer E, Ten Klooster PM, Fledderus M, Veehof M, Baer R. Psychometric properties of the five facet mindfulness questionnaire in depressed adults and development of a short form. Assessment. 2011; 18: 308-320.

19. Neal A, Griffin MA, Hart PM. The impact of organizational climate on safety climate and individual behavior. Saf Sci. 2000; 34: 99-109.

20. Neal A, Griffin MA. A study of the lagged relationships among safety climate, safety motivation, safety behavior, and accidents at the individual and group levels. J Appl Psychol. 2006; 91: 946953.

21. Diener E, Wirtz D, Biswas-Diener R, Tov W, Kim-Prieto C, Choi DW, et al. New measures of wellbeing. In: Assessing well-being. Dordrecht: Springer; 2009. pp.247-266.

22. Kates J, Gerolamo A, Pogorzelska-Maziarz M. The impact of COVID-19 on the hospice and palliative care workforce. Public Health Nurs. 2021; 38: 459-463. 
OBM Integrative and Complementary Medicine 2021; 6(3), doi:10.21926/obm.icm.2103029

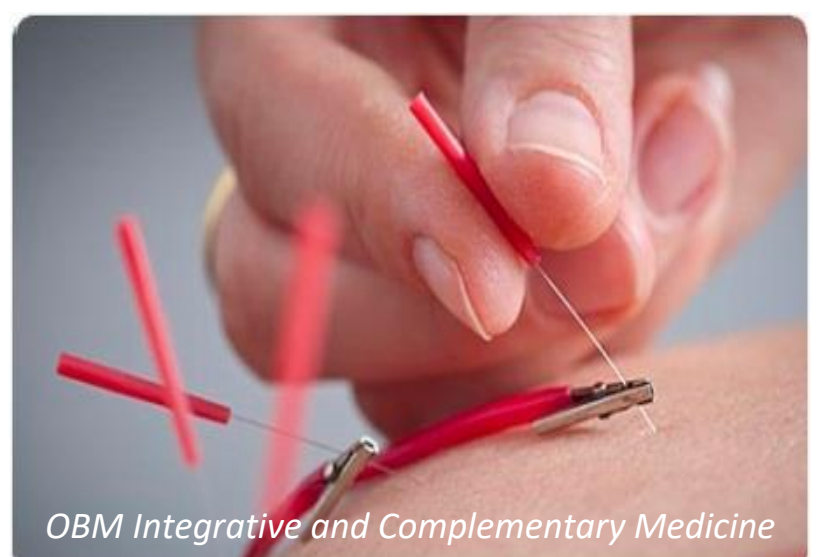

Enjoy $O B M$ Integrative and Complementary Medicine by:

1. Submitting a manuscript

2. Joining in volunteer reviewer bank

3. Joining Editorial Board

4. Guest editing a special issue

For more details, please visit:

http://www.lidsen.com/journals/icm 